\title{
An Increased Efficiency of Triclosan Delivery by Novel Acrylate-Based Nanoparticles
}

\author{
Makarovsky Igor ${ }^{1}$, Boguslavsky Yonit', Lellouche Jonathan ${ }^{2}$, Banin Ehud ${ }^{2}$ and Lellouche Jean-Paul ${ }^{1 *}$ \\ ${ }^{1}$ Institute of Nanotechnology and Advanced Materials, Department of Chemistry, Bar-llan University, Israel \\ ${ }^{2}$ The Mina and Everard Goodman Faculty of Life Science, Institute for Nanotechnology \& Advanced Materials, Bar-Ilan University, Israel
}

\begin{abstract}
Polymeric nanoparticles have been widely investigated as carriers for drug delivery, as they can effectively deliver the drug to a target site and thus increase the therapeutic benefit, while minimizing side effects. Triclosan $\left(\operatorname{Irgasan}^{\circledR}\right.$ ) is a broad-spectrum antimicrobial agent, possessing mostly antibacterial, but also some antifungal and antiviral properties. In order to synergize the advantages of the delivery of antimicrobial molecules of triclosan by a nanoscaled system, we tested antimicrobial nanosized polymeric formulations containing triclosan. Triclosan was derivatized using acrylolyl chloride and then subjected to a radical dispersion polymerization. The polymeric nanoparticles were obtained, namely PTA-NPs, in the range of $100 \mathrm{~nm}$. The characterization of these polymeric nanoparticles as well as the appropriate monomer has been accomplished by nuclear magnetic resonance, scanning and transmitting electron microscopy, elemental and thermal analyses. PTA NPs' electron microscopy examination presents a spherical morphology and a smooth topology. These nanoparticles exhibit very high antimicrobial activities against common pathogens involved in nosocomial infections. We demonstrate the importance of a direct contact of our nanoparticles and the bacterial cell as the trigger to triclosan releasing. Our results emphasize the advantages of a nanoscaled system in a covalently-linked delivery of a biocide and the limitations in utilizing the "free" biocide.
\end{abstract}

Keywords: Polymeric nanoparticles; Dispersion polymerization; Biocide; Triclosan; Antimicrobial activity

\begin{abstract}
Abbreviations: 2-MeEtOH: 2-Methoxyethanol; BPO: Benzoyl peroxide; DSC: Differential scanning calorimetry; EDS: Energy dispersive spectroscopy; ENR: Enoyl-[acyl carrier protein] reductase; EtOH: Ethanol; FDA: Food and drug administration; FTIR: Fourier Transform Infrared Spectroscopy; MBC: Minimal Bactericidal Concentration; $\mathrm{MgSO}_{4}$ :Magnesium sulfate; $\mathrm{MMA}$ :Methylmethacrylate; MS: Mass Spectrometry; NMR: Nuclear Magnetic Resonance; NPs: Nanoparticles; PEG: Poly(ethylene glycol); PEO: Poly(ethylene oxide); PMMA: Poly(methyl methacrylate); PTA: Poly(triclosan acrylate); PVP: Polyvinylpyrrolidone; SEM: Scanning Electron Microscopy; TA: Triclosan acrylate; TEM: Transmitting electron microscopy; TGA: Thermogravimetric analysis; THF: Tetrahydrofuran; TLC: Thin Layer Chromatography; TMB: Tetramethylbenzidine; TMS: Tetramethyl silane
\end{abstract}

\section{Introduction}

Recently, polymeric nanoparticles (NPs) have been widely investigated as carriers for drug delivery [1-5]. There are several routes to introduce the molecule of interest into the polymer-through physical adsorption (loading), covalent attachment, molecular imprinting, etc. The first route takes advantage of the finished polymer as fishing net, in a manner that the desired molecule gets entangled between the polymeric chains and released upon matrix-hydrolysis or an external stimulus (i.e, change in the $\mathrm{pH}$, electric current, solvent preference, etc.) [6]. Alternatively, one can derivatize the molecule of interest into a monomer and then polymerize it. This route greatly increases the potency of the drug, because of its enhanced presence inside the polymer on the one hand, and diminishes the leaching problem on the other hand.

There are several methods to perform polymerization, through suspension, emulsion, dispersion and precipitation polymerization. We have focused on dispersion polymerization in order to optimize the conditions to synthesize the NPs with specific properties.
Briefly, dispersion polymerization involves an initiallyhomogeneous system of a monomer, an organic solvent, an initiator, and a particle stabilizer. The system becomes heterogeneous during polymerization because the polymer is insoluble in the solvent. Polymer particles are stabilized by adsorption of the particle stabilizer on the surface [7]. The process proceeds in the polymer particles as they absorb the monomer from the continuous phase, leading to the formation of spherical particles in the region of about $0.1-10 \mu \mathrm{m}$ in diameter [8,9]. Particle size is governed by the temperature of polymerization, concentrations of the monomer and the initiator, the type and concentration of the stabilizer, and the type of the polymerization medium [10].

In order to synergize the advantages of the molecule of interest with nanomaterials and discard their disadvantages as well, one can physically or covalently link them into one molecular entity. A new system is thus created. Physical entrapment assures a slow release over a certain period of time, and protection from the harsh extra and intracellular environments. Covalent linkage assures these properties and also prevents spontaneously leaking by providing a new sort of control over the system and increases its content in the chosen formulation. One can tailor the properties of the hybrid material as one sees fits.

The antimicrobial agent that was chosen to serve as a model was triclosan (Irgasan'). It is a well-known commercial and a Food and Drug Administration (FDA) approved, synthetic, non-ionic, broad-

*Corresponding author: Lellouche Jean-Paul, Institute of Nanotechnology and Advanced Materials, Department of Chemistry Bar-Ilan University, Ramat-Gan 52900, Israel, E-mail: jp.m.lellouche@gmail.com

Received March 29, 2012; Accepted April 23, 2012; Published April 30, 2012

Citation: Igor M, Yonit B, Jonathan L, Ehud B, Jean-Paul L (2012) An Increased Efficiency of Triclosan Delivery by Novel Acrylate-Based Nanoparticles. J Nanomed Nanotechol S11:001. doi:10.4172/2157-7439.S11-001

Copyright: (c) 2012 Igor M, et al. This is an open-access article distributed under the terms of the Creative Commons Attribution License, which permits unrestricted use, distribution, and reproduction in any medium, provided the original author and source are credited. 
spectrum antimicrobial agent, possessing mostly antibacterial, but also some antifungal and antiviral properties [11]. Numerous studies conducted on different bacteria strains showed that triclosan acts on a defined bacterial target in the bacterial fatty acid biosynthetic pathway, the NADH-dependent enoyl-[acyl carrier protein] reductase (ENR) [12-15].

Several studies have already shown that triclosan could be loaded into an organic matrix, such as polystyrene, $\beta$-cyclodextrin, and several copolymers and still exhibit its antibacterial properties [16-24]. Nevertheless, the "free" triclosan released from these composites has several disadvantages. It may undergo chlorination under conditions typical to water treatment [25]; it may undergo photolytic, hydrolytic, and degradative transformations (into dioxins) at various wavelengths and at various $\mathrm{pH}$ values [26]; and if accumulated, either in the environment or on the human tissue, it may be harmful [27].

To reduce the creation of undesirable triclosan derivatives, a polymer and various copolymers (polyurethane based coatings containing tethered triclosan groups) have also been prepared out of triclosan, though it was never synthesized as nanospheres, only as a bulk [28-31].

Synthesizing a nanosphered polymer composed of covalently bound triclosan as the basic ingredient, combines the various advantages of the single systems. The polymer assures better protection against both hydrolytic and photolytic degradation and prevents the active compound from leaching. Moreover, the nanometer scale increases the overall surface area per gram of the particles and so diminishes the amount of triclosan needed, making the overall composition less toxic. The covalent bond between the polymeric backbone and the biocide is designed to be broken by enzymes, subsequently releasing the active triclosan, which will act upon its target inside the cell. Basically, the enzymes produced by the bacteria themselves will be responsible for the release of the antimicrobial agent. Our group has already reported on an analogous system, namely nanosized particulate $\mathrm{SiO}_{2}$ matrix that upon enzymatic degradation could release triclosan, in a controlled manner [32]. The system possessed enhanced antibacterial properties as compared to the free biocide.

Herein a facile and convenient route to prepare polymeric NPs, containing covalently-bound triclosan, is reported. This system is of a chemically different nature, than the one reported before, and intrinsically biodegradable. Optimization experiments were conducted and subsequently the NPs were fabricated according to the chosen synthetic pathway, using dispersion polymerization. Full characterization of the polymeric NPs and the effects of various parameters (i.e., monomer and surfactant concentrations) on the polymerization process are described. Furthermore, we have tested these novel NPs against common pathogens and observed a high antibacterial activity triggered by enzymatic cleavage of triclosan from the polymeric matrix.

\section{Experimental}

\section{Material and chemicals}

The following analytical-grade chemicals were purchased from Aldrich and were used without further purification: irgasan (triclosan) (>97\%), ethanol (HPLC), 2-methoxyethanol (99.8\%), toluene (99.8\%), ethanol (HPLC), toluene (99.8\%), Tetrahydronfurane (THF) ( $\geq 99.9 \%)$, triethylamine $(99.5 \%)$, acryloyl chloride (96\%), dibenzoyl peroxide (98\%), PVP $(\mathrm{Mw}=360 \mathrm{KDa})$, magnesium sulfate $\left(\mathrm{MgSO}_{4}\right)$ (drying agent). Water was purified by the passage of deionized water through an Elgastat Spectrum reverse osmosis system (Elga Ltd., High Wycombe, UK).

\section{Analytical methods and instrumentation}

${ }^{1} \mathrm{H}$ and ${ }^{13} \mathrm{C}$ nuclear magnetic resonance (NMR) spectra were obtained on a Bruker DPX $300 \mathrm{MHz}$ spectrometer. Chemical shifts are expressed in ppm downfield from $\mathrm{Me}_{4} \mathrm{Si}$ (TMS) used as an internal standard. The values are given in the $\delta$ scale. Multiplicities in the ${ }^{13} \mathrm{C}-\mathrm{NMR}$ spectra were determined by off-resonance decoupling. All moisture sensitive reactions were carried out in flame dried reactions vessels. Melting points were determined on a digital melting point apparatus (ELECTROTHERMAL, England). Progress of the reactions was monitored by thin layer chromatography (TLC).

Mass spectra (MS) and high-resolution mass spectra (HRMS) were obtained on a MICROMASS-AutoSpec high resolution magnetic sector mass spectrometer connected to a HP-5890 series II gas chromatograph $\left(\mathrm{CI}^{+}\right.$, chemical ionization $)$

High resolution scanning electron microscopy (HR-SEM) and Energy Dispersive Spectroscopy (EDS) analyses were executed on a JEOL JSM-7000F instrument. Transmission electron microscope (TEM) and HR-SEM analyses enabled the determination of morphology, size and size distribution of particles, while EDS and elemental analyses provided particle composition data. TEM micrographs were taken on a Tecnai Spirit instrument $(120 \mathrm{kV})$. Samples for TEM were prepared by placing a drop of the diluted spheres dispersed in an (50\% v/v) ethanolwater solution on 400 mesh carbon-covered $\mathrm{Cu}$ grids $\mathrm{Pk} / 100$ (SPI Supplies West Chester, USA) and then air-dried. Average diameters, particle size distribution, and surface morphologies of the fabricated particles were obtained by SEM or TEM, followed by statistical analysis (ImageJ 1.43u software, measurement of at least 200 particles per sample). SEM samples were coated with a thin layer of gold by a sputtering deposition technique.

Thermal measurements were performed by thermogravimetric analysis (TGA) and differential scanning calorimetry (DSC). TGA measurements were carried out on a TA Instruments apparatus (1GA Q500 model) for TGA and DSC on a METTLER TOLEDO DSC $822^{\circ}$ using a $25-500^{\circ} \mathrm{C}$ temperature profile $\left(10^{\circ} \mathrm{C} \mathrm{m^{-1 }}, \mathrm{N}_{2}\right.$ atmosphere, 100 mlmin $^{-1}$ ) for both. TGA afforded temperature profiles of polymeric particles vs. TA. DSC disclosed endothermic and exothermic processes involving the polymeric NPs vs. the monomer during the heating process.

Elemental (chlorine) analysis of the NPs was performed using a combination of an oxygen flask combustion technique and a subsequent ion chromatography (DIONEX). The relative quantity of Triclosan was calculated according to equation (1):

$$
\begin{aligned}
& \frac{\mathrm{mol}_{f}(\mathrm{Cl})}{3} \times 289.64 \frac{\mathrm{gr}}{\mathrm{mol}}\left(M_{W} \text { of Triclosan }\right) \\
& =\% \text { Triclosan inside the PTA NPS }
\end{aligned}
$$

where $\mathrm{mol}_{f}$ indicates the amount of chlorine in moles found by elemental analysis. The expression is divided by 3 , due to the presence of 3 chlorine atoms in the triclosan molecule. If one assumes that the found amount of chlorine relates to an arbitrary 100 mass units, the expression result indicates percentages.

Fourier transform infrared (FT-IR) analysis was performed on an FT-IR Brüker Equinox 55 spectrometer. The analysis was performed with $13 \mathrm{~mm}$ diameter $\mathrm{KBr}$ pellets that contained $2 \mathrm{mg}$ of the sample and $198 \mathrm{mg}$ of $\mathrm{KBr}$. The pellets were subjected to 200 scans at $4 \mathrm{~cm}^{-1}$ resolution. 
A UV-spectrophotometer (CARY 100 Bio UV-VIS spectrophotometer) was utilized to further characterize TA and the resulting PTA NPs (due to the presence of UV active chromophore).

\section{Synthesis of 5-chloro-2-(2,4-dichlorophenoxy)phenyl acry-} late (TA)

TA was synthesized according to a modified procedure adapted from Cho et al. [28]. Briefly, to a solution of triclosan [5-chloro-2-(2,4dichlorophenoxy)phenol] ( $1 \mathrm{eq}, 6 \mathrm{gr}, 20.7 \mathrm{mmol}$ ) in dry tetrahydrofuran (THF, $20 \mathrm{ml}$ ) at room temperature was added dropwise in the course of 30 minutes triethylamine $(0.94 \mathrm{eq}, 2.7 \mathrm{ml}, 19.4 \mathrm{mmol})$ and stirred until a clear solution was obtained. A solution of acryloyl chloride (0.94 eq, $1.58 \mathrm{ml}, 19.4 \mathrm{mmol})$ in THF $(5 \mathrm{ml})$ was then added via a dropping funnel. The end of the dropwise addition was characterized by a change of the colorless solution to an opaque-white suspension. The mixture was stirred overnight at room temperature. The reaction was monitored by TLC (9:1 n-Hx: $\left.\mathrm{Et}_{2} \mathrm{O}\right)$. The solvent was evaporated to obtain an off-white tar. The crude residue was dissolved in diethyl ether and extracted with $1 \mathrm{M} \mathrm{NaOH}$ three times. The organic phases were combined, dried over $\mathrm{MgSO}_{4}$ and evaporated. The product, TA was obtained as clear oil in $83 \%$ yield $(5.88 \mathrm{~g}) .{ }^{1} \mathrm{H}$ NMR $(300 \mathrm{MHz}$, $\left.\mathrm{CDCl}_{3}\right) \delta 7.43(\mathrm{~d}, J=2.5 \mathrm{~Hz}, 1 \mathrm{H}, \mathrm{ClCCHCCl}), 7.25(\mathrm{~d}, J=2.5 \mathrm{~Hz}, 1 \mathrm{H}$, ClCCHCO), 7.19 (dd, $J=6.1,2.5 \mathrm{~Hz}, 1 \mathrm{H}, \mathrm{ClCCHCHC(O)CCl),} 7.16$ $(\mathrm{dd}, J=6.1,2.5 \mathrm{~Hz}, 1 \mathrm{H}, \mathrm{ClCCHCHC}(\mathrm{O}) \mathrm{C}(\mathrm{O})), 6.88(\mathrm{~d}, J=6.7 \mathrm{~Hz}$, $1 \mathrm{H}, \mathrm{ClCCHCHC}(\mathrm{O}) \mathrm{C}(\mathrm{O})), 6.85(\mathrm{~d}, J=6.7 \mathrm{~Hz}, 1 \mathrm{H}, \mathrm{ClCCHCHC}(\mathrm{O})$ $\mathrm{CCl}), 6.51(\mathrm{dd}, J=17.3,1.2 \mathrm{~Hz}, 1 \mathrm{H}, \mathrm{CHCH} \boldsymbol{H}$ trans $), 6.22(\mathrm{dd}, J=$ 17.3, $10.4 \mathrm{~Hz}, 1 \mathrm{H}, \mathrm{CHCH}_{2}$ ), 5.98 (dd, $J=10.4,1.2 \mathrm{~Hz}, 1 \mathrm{H}, \mathrm{CHCH} \boldsymbol{H}$ cis); ${ }^{13} \mathrm{C}$ NMR $\left(75.5 \mathrm{MHz}, \mathrm{CDCl}_{3}\right) \delta 163.4(\mathrm{OC}=\mathrm{O}), 151.2(\mathrm{CHC}(\mathrm{O})$ $\mathrm{C}(\mathrm{O})), 146.8(\mathrm{ClCC}(\mathrm{O})), 141.7(\boldsymbol{C}(\mathrm{O}) \mathrm{C}=\mathrm{O}), 133.6\left(\mathrm{CHCH}_{2}\right), 130.5$ $(\mathrm{ClCCHCCl}), 129.6(\mathrm{ClCCHC}(\mathrm{O})), 129.4(\mathrm{ClCCHCClC}(\mathrm{O})), 128.3$ $(\mathrm{ClCCHCHC}(\mathrm{O}) \mathrm{CCl}), 127.2\left(\mathrm{CHCH}_{2}\right), 126.9(\mathrm{ClCCHCHC}(\mathrm{O}) \mathrm{C}(\mathrm{O}))$, 126.1 ( $\mathrm{ClCCHCClC}(\mathrm{O})), 124.6$ ( $\mathrm{ClCCHCO}), 120.6$ ( $\mathrm{ClCCHCHC}(\mathrm{O})$ $\mathrm{CCl}), 120.4(\mathrm{ClCCHCHC}(\mathrm{O}) \mathrm{C}(\mathrm{O}))\left(\right.$; MS (Magnet $\left.\mathrm{CI}^{+}\right) \mathrm{m} / z 343.95\left(\mathrm{M}^{+}\right.$, 30.39), $287.95\left(\left[\mathrm{C}_{12} \mathrm{H}_{6} \mathrm{C}_{13} \mathrm{O}_{2}\right], 6.10\right)$; HRMS calcd for $\mathrm{C}_{15} \mathrm{H}_{9} \mathrm{Cl}_{3} \mathrm{O}_{3}\left(\mathrm{M}^{+}\right)$ 343.959 found 343.955 .

\section{Dispersion polymerization procedure to fabricate poly (triclosan acrylate) (PTA) or PMMA NPs}

In a typical experiment, nanometer sized PTA nanoparticles with an average diameter of $95 \pm 25 \mathrm{~nm}$ were formed by dissolving TA ( 0.4 $\mathrm{g}, 1.38 \mathrm{mmol}), \mathrm{BPO}(10 \mathrm{mg}, 0.04 \mathrm{mmol})$, and PVP $(360 \mathrm{kD}, 0.1 \mathrm{~g})$ in a 2.4:1 mixture of EtOH (7.2 ml) and 2-MeEtOH (3 ml). The total volume of the solution was $10.2 \mathrm{ml}$ and the TA, BPO, and PVP concentrations were $4,0.1$ and $1 \%(\mathrm{w} / \mathrm{v})$, respectively. For the polymerization of $\mathrm{TA}$, the vial was shaken at $73^{\circ} \mathrm{C}$ for $6 \mathrm{~h}$. The resulting particles were washed by 6 intensive centrifugation cycles $(14,550 \mathrm{rcf})$ with ethanol and then dried under vacuum at $40^{\circ} \mathrm{C}$. PTA nanoparticles of various sizes, size distributions and stabilities were prepared by changing the polymerization parameters, e.g. TA and initiator concentrations, type and concentration of the polymeric surfactant, time of reaction of the polymerization system, and co-solvent concentration.

PMMA nanoparticles were synthesized using a similar procedure as one described above for the PTA NPs, using methyl methacrylate (MMA) as the monomer. These NPs were prepared in order to utilize them as a blank reference of the antibacterial activity of the bare polyacrylate matrix.

\section{Bacterial cultures and growth conditions}

E. coli 1313 and S. aureus 8325 (clinical isolates) were grown in Tryptic Soy Broth (TSB, Difco) and Tryptic Soy Broth 66\% supplemented with glucose $0.2 \%$ (TSB-Glu) media respectively at $37^{\circ} \mathrm{C}$. E. coli W3110 (pBluescript) is sensitive to triclosan and introduction of the FabK expression vector ( $\mathrm{pFabK}$ ) increased the minimum inhibitory concentration (MIC) for triclosan to $2000 \mu \mathrm{g} \mathrm{ml}^{-1}$ (i.e., resistant strain) [33]. E. coli W3110 was grown in Tryptic Soy Broth (TSB, Difco). Cell growth was followed by measuring the absorbance for $24 \mathrm{~h}$ at an optical density of $595 \mathrm{~nm}\left(\mathrm{OD}_{595}\right)$ using a microplate reader (Synergy 2, BioTek Instruments, Winoosky).

\section{Killing curves assay}

Killing curves were determined in triplicate using starting inocula of $10^{6} \mathrm{CFU} \mathrm{ml} \mathrm{m}^{-1}$. Overnight cultures of bacteria in TSB or TSB-Glu were diluted as necessary to produce the desired starting inocula in 10 $\mathrm{ml}$ of medium. NPs samples (i.e., PTA and PMMA NPs) were added at a concentration range from 0 to $50 \mu \mathrm{g} \mathrm{ml}^{-1}$. Triclosan was tested at two different concentrations of 0.36 and $0.44 \mu \mathrm{g} \mathrm{ml}^{-1}$ for E. coli and $S$. aureus, respectively. Samples $(100 \mu \mathrm{L})$ were removed from each well every 2 hours and diluted appropriately in saline. Colony-forming units (CFU) were determined by spotting $5 \mu \mathrm{L}$ of serial dilution samples (in triplicate) on Luria-Bertani agar plates after 24 hours incubation at $37^{\circ} \mathrm{C}$.

\section{High resolution scanning electron microscopy of bacterial samples}

Samples of S. aureus and E. coli cultures treated for 1 hour with PTA NPs $\left(50 \mu \mathrm{g} \mathrm{ml}^{-1}\right)$ were fixed with glutaraldehyde and paraformaldehyde for 1 hour. Following incubation, samples were washed twice with a phosphate buffer saline (PBS) without $\mathrm{Ca}^{2+}$ and $\mathrm{Mg}^{2+}$. Samples were then immersed for 1 hour in titanic acid and a glutamate solution at 4:5 concentrations ratio, respectively. Samples were then washed twice with $\mathrm{PBS}$ and exposed to an aqueous osmium tetroxide $\left(\mathrm{OsO}_{4}\right.$, SigmaAldrich Israel, Rehovot) solution for 1 hour. For sample dehydration, the samples were sequentially washed with $\mathrm{H}_{2} \mathrm{O}-\mathrm{EtOH}$ and $\mathrm{EtOH}-$ Freon solutions (concentrations ranging from $50 \%$ to $100 \%$ for each solvent). Finally, samples were dried in air, chromium-coated and examined using a FEI MagellanL (accelerating voltage of 3 or $5 \mathrm{kV}$ ) high-resolution scanning electron microscope (FEI, Hillsboro, Oregon, USA).

\section{Triclosan quantification}

Triclosan concentrations have been monitored using a Triclosan IA kit developed and supplied by Abraxis LLC (Warminster, USA). E. coli and $S$. aureus samples incubated with PTA NPs at a concentration of $50 \mu \mathrm{g} \mathrm{ml}^{-1}$ were taken for a period of $10 \mathrm{~h}$ at regular intervals of $1 \mathrm{~h}$ using the same conditions as described above (see killing curve assays). To determine the concentration of triclosan released from NP samples, samples $(100 \mu \mathrm{L})$ were treated with $10 \%$ ice-cold trichloroacetic acid for cell lysis and then analyzed.

The Triclosan IA kit is based on (i) polyclonal antibodies coated on microtiter wells, and on (ii) the competitive reaction between triclosan and the enzyme-labeled triclosan for antibody binding sites present on the wells. The assay was performed according to the protocol provided by the manufacturer. Briefly, samples of $150 \mu \mathrm{L}$ (1:30000 titers) of a suspended triclosan-specific antibody were mixed in a glass test tube and incubated at room temperature for $30 \mathrm{~min}$. After this period, 250 $\mu \mathrm{L}$ of HRP-4-[3-bromo-4-(2,4-dibromophenoxy)phenoxy]butyrate were added and the mixture incubated for an additional $30 \mathrm{~min}$ (room temperature). At completion of incubation, the wells were washed three times with $\mathrm{H}_{2} \mathrm{O}$ to remove unbound agents. The chromagen, 3,3',5,5'-tetramethylbenzidine (TMB), and hydrogen peroxide 
Citation: Igor M, Yonit B, Jonathan L, Ehud B, Jean-Paul L (2012) An Increased Efficiency of Triclosan Delivery by Novel Acrylate-Based Nanoparticles. J Nanomed Nanotechol S11:001. doi:10.4172/2157-7439.S11-001

$(500 \mu \mathrm{L})$, were added to the wells and the mixture was incubated for 20 min (room temperature). The color development reaction was stopped by the addition of $500 \mu \mathrm{L}$ of $2 \%(\mathrm{v} / \mathrm{v})$ of a sulphuric acid solution, after which the absorbance was read at $450 \mathrm{~nm}$ within $15 \mathrm{~min}$. The data presented is an average of at least three independent experiments. Standard curves were prepared by testing increasing concentrations of triclosan from 20 to $1000 \mathrm{ngL}^{-1}$. The standard curves were fitted to a four-parameter equation according to the following formula (2):

$$
\mathrm{A}=\mathrm{D}+\frac{T-D}{1+10^{\left(\log I C_{50}-\log c\right) \times H S}}
$$

where $A$ is the absorbance, $T$ is the maximal absorbance, $D$ is the minimum absorbance, $\mathrm{IC}_{50}$ is the concentration producing $50 \%$ of the maximal absorbance, $c$ is the standard concentration, and HS is the slope at the inflection point of the sigmoid curve (inset in Figure 8). Triclosan concentrations were determined for each sample by dividing the sample mean absorbance (B) by the mean absorbance value for the zero standards $\left(\mathrm{B}_{0}\right.$, without triclosan) and normalizing with the respective CFU counts.

\section{Results and Discussion}

\section{TA's and PTA NPs' syntheses and characterization}

Triclosan acrylate (TA) was synthesized according to a modified procedure adapted from Cho et al. [28], as shown in scheme 1, via an organic base-mediated acryloylation using triclosan and acryloyl chloride. The structure of TA was confirmed by ${ }^{1} \mathrm{H}$ and ${ }^{13} \mathrm{C}-\mathrm{NMR}$ experiments. Poly(triclosan acrylate) (PTA) NPs were obtained via a dispersion polymerization technique. Figure 1 depicts typical TEM and SEM micrographs of dried PTA NPs, prepared using the optimal conditions described above. Typically, aggregates were formed as a result of sample preparation for TEM analysis. Nevertheless, the contour of each NP was clearly distinguished with an average diameter of $95 \pm 25 \mathrm{~nm}$. Both TEM and SEM images (Figures $1 \mathrm{~A}$ and $1 \mathrm{~B}$ ) revealed the spherical morphology of these NPs. SEM completed the optical evaluation and gave an insight as to the smooth topology of PTA NPs (Figure 1B). The PTA NPs lacked any traces of the monomer, as indicated both by FTIR and ${ }^{1} \mathrm{H}-\mathrm{NMR}$ studies. Figure 2 shows the characteristic IR spectra of both the monomer (Figure 2A) and the polymeric NPs (Figure $2 \mathrm{~B}$ ). It could clearly be seen that a $\mathrm{C}=\mathrm{C}$ double bond stretching present in Figure $2 \mathrm{~A}$ at about $1675 \mathrm{~cm}^{-1}$ was lacking from the spectrum in Figure 2B, despite the coincident presence of the rest of the peaks. ${ }^{1} \mathrm{H}-\mathrm{NMR}$ further verified the success of the polymerization reaction by the lack of 3 vinylic protons at 5.98, 6.21, and $6.51 \mathrm{ppm}$ and the appearance of aliphatic peaks at $2.8 \mathrm{ppm}$. Elemental analysis performed on the NPs revealed $31.22 \% \mathrm{Cl}$ content, meaning that $85 \%$ of the content of the polymeric NPs was due to the presence of triclosan (calculated using equation 1). The rest of the organic content consisted of the backbone originated from the acrylate moiety and the adsorbed surfactant used in order to stabilize the formation of the NPs.

Figure S1 illustrates the thermal analysis conducted on the PTA NPs. The solid curve corresponds to the thermogravimetric analysis (TGA). One main steep slope (Figure S1A) present in the thermograph (ca. $94 \%$ weight loss) between $350-450^{\circ} \mathrm{C}$ was indicative of a single degradation process. The differential scanning calorimetry (DSC) thermograph of PTA (Figure S1B) confirmed this fact, as indicated by the endotherm between $380-420^{\circ} \mathrm{C}$ with a peak at ca. $410^{\circ} \mathrm{C}$. The dominant peak at $410^{\circ} \mathrm{C}$ was followed immediately by a series of exothermic peaks that might indicate the combination of two chloride radicals into $\mathrm{Cl}_{2}$. This behavior was not surprising for halogenated aromatic compounds and has already been described by Almog and Levy [34]. The DSC thermograph also revealed another endothermic process, the glass transition $\left(\mathrm{T}_{\mathrm{g}}\right)$ of the polymer, at $87^{\circ} \mathrm{C}$.

\section{Optimization of the polymerization process}

Among the various parameters studied in order to optimize the polymerization conditions were monomer concentration, and various surfactants/stabilizers and their corresponding concentrations. Figure 3 presents the influence of the TA concentration on the size and size

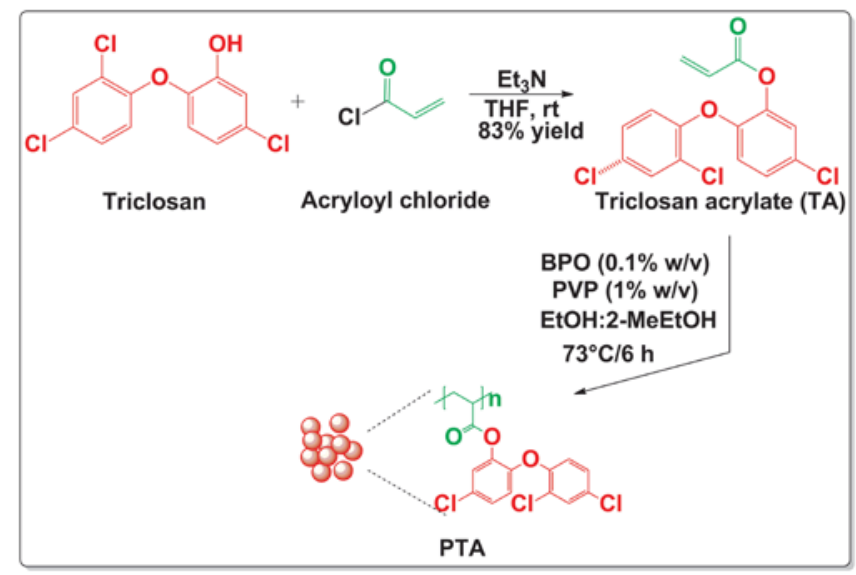

Scheme 1: Synthesis of TA monomer and the fabrication of PTA NPs
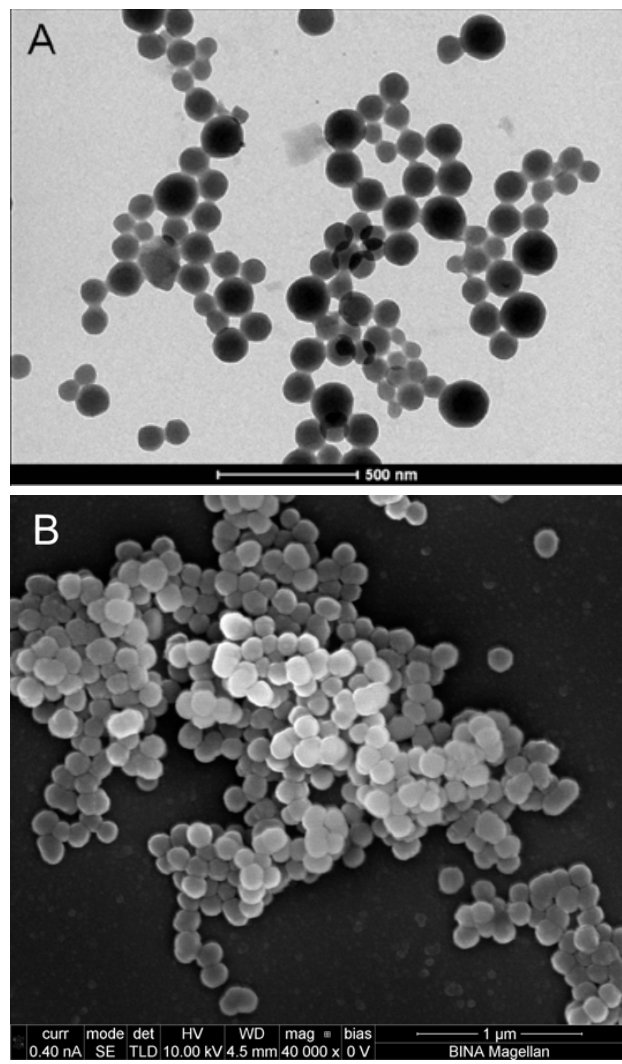

Figure 1: $(A)$ TEM (scale bar $=500 \mathrm{~nm})$ and $(B)$ SEM $($ scale bar $=1000 \mathrm{~nm})$ microphotographs of PTA NPs. 


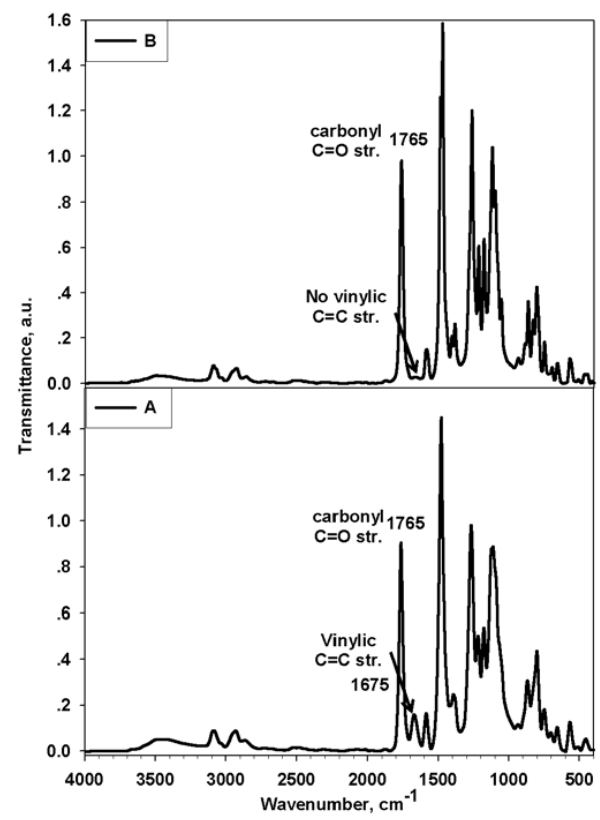

Figure 2: FTIR spectra of (A) triclosan acrylate monomer and (B) poly(triclosan acryalte) NPs.

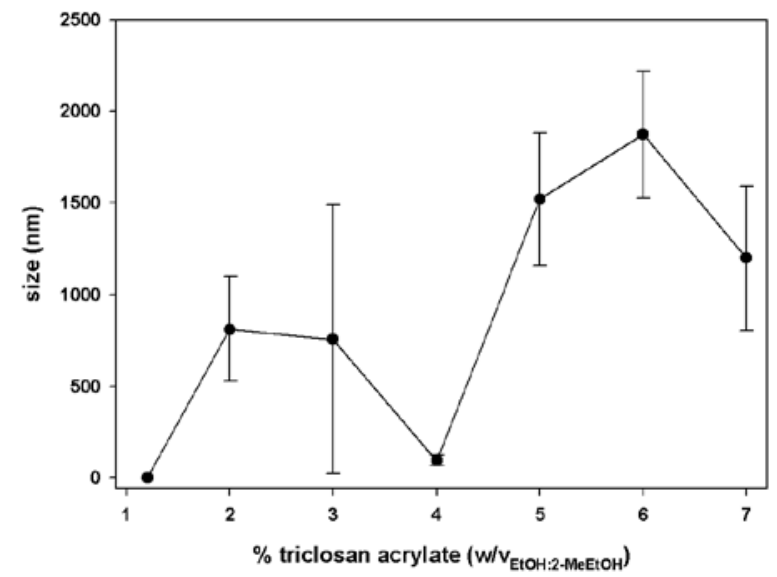

Figure 3: Effect of TA concentration on the size and size distribution of the polyTA NPs.

distribution of the PTA NPs. This figure shows that there was an optimum in the concentration of the monomer. In the presence of less than $2 \%(\mathrm{w} / \mathrm{v})$ monomer, the reaction did not take place. Between $2-3 \%$ $(\mathrm{w} / \mathrm{v})$, the average size of the NPs was around $800 \mathrm{~nm}$. Over $4 \%(\mathrm{w} / \mathrm{v})$ of the monomer, one can observe the tendency to increase in diameter with an increase in the monomer concentration. This was generally true for other polymerization systems as well, as reported by Boguslavsky et al. [35]. This effect was rather drastic and as shown in Figure 3, the particles were obtained in the micrometer scale. One could thus observe that the optimal monomer concentration to form nano-scale particles was around $4 \%(\mathrm{w} / \mathrm{v})$. It is possible to assume that this optimum was the result of a compromise between the minimal monomer concentration needed in order to create the primary nucleation centers and the point at which too much of the monomer caused the particles to increase in size due to $\pi$-stacking between the chlorinated phenyl rings.

After testing several non-ionic surfactants, such as PVP and several polyethylene glycols (PEGs) with different molecular weights, listed in Table 1, it was found that PVP with a molecular weight of $360 \mathrm{kD}$ was the appropriate stabilizer to obtain NPs with the desirable diameter. The hydrophilic surfactants [poly(ethylene oxide)s PEO, 300 and 600 $\mathrm{kD}$ ] with a high molecular weight were not miscible in the ethanolmethoxyethanol solution and gave no particulate products at all. Another set of experiments were designed to determine the appropriate concentration of PVP $(360 \mathrm{kD})$ needed to obtain the desired NP diameter. Figure 4 summarizes the influence PVP concentration had on the size and the size distribution of the formed PTA NPs. It can be seen that increasing the concentration of the stabilizer, increased the particle diameter. Apparently, increasing the stabilizer's concentration caused its amplified adsorption on the growing particle and thus augmented its diameter. The optimal concentration of PVP was found to be $1 \%$, with $4 \%$ monomer. To summarize, the optimal system requirements to form nano scaled particles were found to be $4 \%(\mathrm{w} / \mathrm{v})$ of monomer with $1 \%(\mathrm{w} / \mathrm{v})$ of PVP $(360 \mathrm{kD})$.

\section{Antibacterial properties of PTA NPs}

In order to investigate the antimicrobial activity of these NPs, a series of experiments were designed and carried out. Figure 5 depicts the antimicrobial activity of PTA NPs against two common bacterial pathogens, Escherichia coli (Gram negative) and Staphylococcus aureus (Gram positive) in the presence of different concentrations of NPs. The present results demonstrated that for both bacteria, PTA NPs

\begin{tabular}{lll}
\hline Name & Mw $\left(\mathbf{g ~ m o l}^{-1}\right)$ & Diameter $( \pm \mathbf{s t d e v})$ \\
\hline PVP & 10,000 & $690( \pm 450)$ \\
& 50,000 & $820( \pm 470)$ \\
& 360,000 & $95( \pm 25)$ \\
& $1,300,000$ & $970( \pm 1005)$ \\
PEG & 10,000 & $1120( \pm 185)$ \\
PEO & 300,000 & - \\
& 600,000 & - \\
\hline
\end{tabular}

Table 1: Effect of different non-ionic surfactants [1\% w/v (EtOH: 2-MeEtOH)] on size and size distribution of PTA NPs.

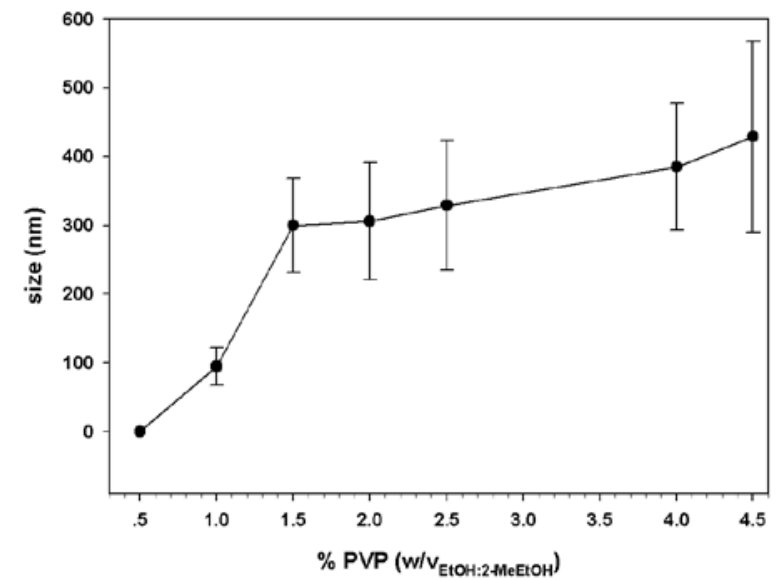

Figure 4: Effect of PVP concentration on the size and size distribution of the polyTA NPs. 
caused a reduction in growth in a dose-dependent manner and the minimal bactericidal concentration (MBC) measured was $10 \mu \mathrm{g} \mathrm{ml}^{-1}$ and $25 \mu \mathrm{g} \mathrm{ml}^{-1}$ for E. coli and S. aureus, respectively. The kinetics of the antimicrobial activity was somewhat different for the two bacteria. For E. coli, a 5-hour lag time was first evident after which complete killing was detected at 14 hours. S. aureus had a similar lag time and complete killing was achieved after 12 hours, though obtained with a higher concentration of particles.

Next, we wanted to rule out the possibility of leaching of triclosan from the polymeric NPs, without the presence of bacteria, which would suggest that the PTA NPs were unstable at the tested conditions. The highest tested concentration of PTA NPs $\left(50 \mu \mathrm{g} \mathrm{ml}^{-1}\right)$ was incubated in a growth medium (without bacteria) for 24 hours (same conditions as for killing experiments mentioned above). Then, the NPs were centrifuged; the supernatant filtered and incubated with both $E$. coli and $S$. aureus and growth was monitored. No inhibition of growth could be observed either for the NPs or for the controls (Figures 5A and $5 \mathrm{~B})$. This strongly suggested that the antimicrobial activity required the presence of bacteria and that either no triclosan was released from the PTA NPs in the first incubation step or the amount of released triclosan remained very low and was not sufficient to inhibit bacterial growth.

In order to try to establish the biochemical mechanism by which these NPs act, it was important to confirm that triclosan was indeed the main cause of the observed antimicrobial activity. As was mentioned in the introduction, triclosan inhibits the ENR enzyme in the fatty acid biosynthesis cycle. This inhibition occurs by forming a tight, non-covalent ternary complex with the oxidized cofactor $\mathrm{NAD}^{+}$in the active site of the enzyme [36-38]. A triclosan-resistant E. coli strain that contained a pFabK plasmid (i.e., an over-expressive FabK) was grown in the presence of triclosan containing NPs, while a pBluescript was used as a control plasmid. If triclosan was the real cause of the observed antibacterial properties of the afore-mentioned NPs, two observations were expected. First, the triclosan-resistant strain of $E$. coli had to remain resistant and grow normally due to the inhibitory action of pFabK upon triclosan release (Figure 6). Also, the strain that contained the control pBluescript plasmid must behave as a normal strain of $E$. coli and remain inhibited in the presence of free triclosan or of triclosan-containing particles (Figure 6). As a negative control we added to the growth medium, containing the pFabK E. coli, poly(methyl methacrylate) (PMMA) NPs, containing no triclosan and having no antimicrobial activity on their own [39]. As can be seen in Figure 6, bacteria that carried the pFabK plasmid grown in the presence of triclosan, PMMA or PTA NPs showed normal exponential growth curves. In contrast, the strains carrying the pBluescript control plasmid remained sensitive to triclosan and their growth was inhibited (lower growth curves presented in Figure 6). It may be assumed that the minimal growth observed for the pBluescript-carrying bacteria exposed to PTA NPs was caused by the activation time needed for the NPs to act; present in the killing curves as well (Figure 5). These experiments emphasized the role of released triclosan in mediating the antibacterial activity of polymeric NPs that contained covalently attached biocide.

These data is consistent with the results shown in Figure 7 , presenting the amount of free triclosan released from the polymeric NPs in the presence of bacteria. The maximal triclosan concentrations that were recovered 3 and 2 hours after the primary release from PTA NPs were $0.36 \mu \mathrm{g} \mathrm{ml}^{-1}$ and $0.44 \mu \mathrm{g} \mathrm{ml}^{-1}$ for E. coli and S. aureus, respectively. These concentrations represent $0.85 \%$ and $1.04 \%$ of the theoretical maximal triclosan concentration in the polymeric NPs, correspondingly. At this point, the biocide concentration reached
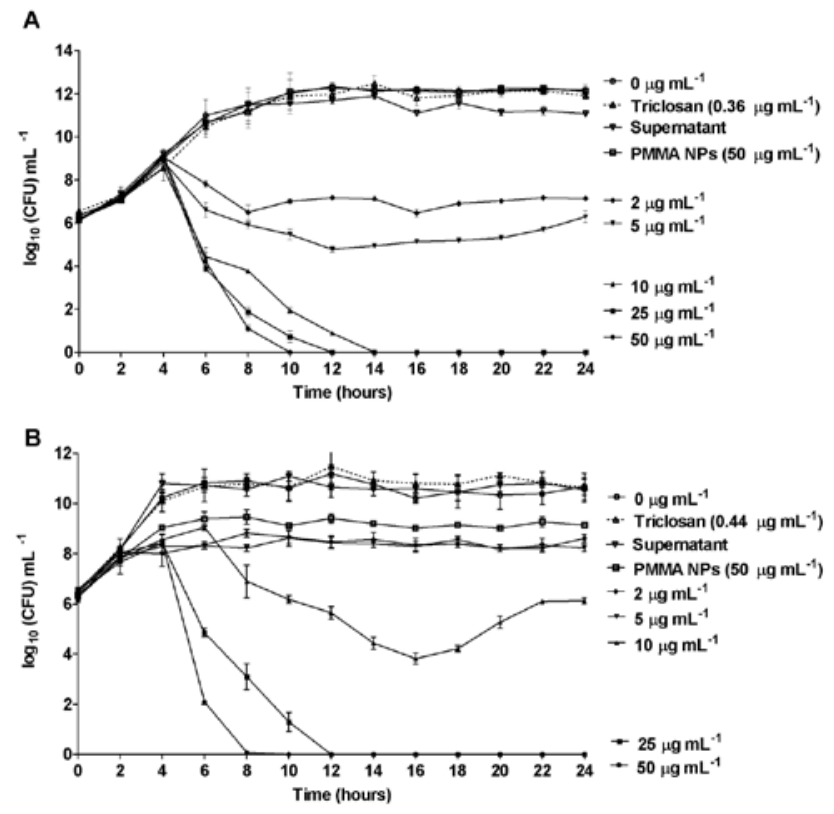

Figure 5: Antibacterial properties of TPA NPs. Killing curves of (A) E. coll and (B) S. aureus grown in different concentrations of PTA NPs (2 to 50 $\mu \mathrm{g} \mathrm{mL}-1)$ for $24 \mathrm{~h}$ at $37^{\circ} \mathrm{C}$. Growth was determined by viable counts and is expressed in colony-forming units (CFU). Untreated bacteria and unloaded NPs (i.e., PMMA NPs) tested at a concentration of $50 \mu \mathrm{g} \mathrm{mL}{ }^{-1}$ served as controls. Dashed lines (in A and B) represent the killing curves of $E$. coli (A) and $S$. aureus $(B)$ exposed to free triclosan at concentrations of 0.36 and $0.44 \mu \mathrm{g} \mathrm{mL} \mathrm{L}^{-1}$, respectively. The triclosan concentrations tested in $A$ and $B$ were determined as the maximal concentrations of triclosan released from PTA NPs in the presence of $E$. coli and $S$. aureus, respectfully (see Figure $7)$. The supernatant curve line refers to $E$. coli $(A)$ and $S$. aureus $(B)$ grown in the supernatant of TSB or TSB-Glu previously incubated with PTA NPs (50 $\mu \mathrm{g} \mathrm{mL} \mathrm{L}^{-1}$ ) for $24 \mathrm{~h}$ at $37^{\circ} \mathrm{C}$. Error bars represent the standard deviation of three independent experiments conducted in triplicate.

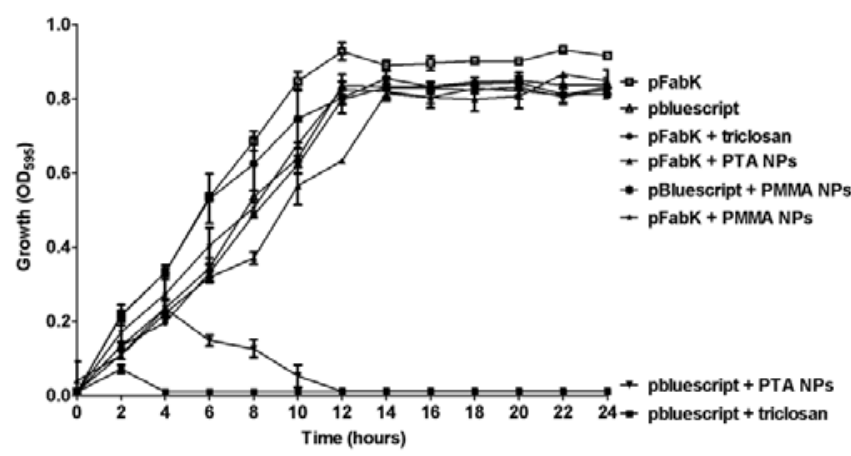

Figure 6: Triclosan-mediated bactericidal properties of PTA NPs. Growth curves of $E$. coli W3110 containing a triclosan resistant plasmid pFabK and a control plasmid pBluescript in the presence of PTA NPs $\left(50 \mu \mathrm{g} \mathrm{mL}^{-1}\right)$, PMMA $\mathrm{NPs}$, and triclosan $\left(100 \mu \mathrm{g} \mathrm{mL}^{-1}\right)$. Error bars represent the standard deviation of three independent experiments conducted in triplicate.

a plateau that was maintained for at least 10 hours. In fact, given the theoretical maximal triclosan concentration ( $85 \%$ of the mass of each NP is a covalently tethered triclosan), the NPs could serve as triclosan reservoir and act as a controlled release system, active for a much longer period than the same concentration of free triclosan. Interestingly, 


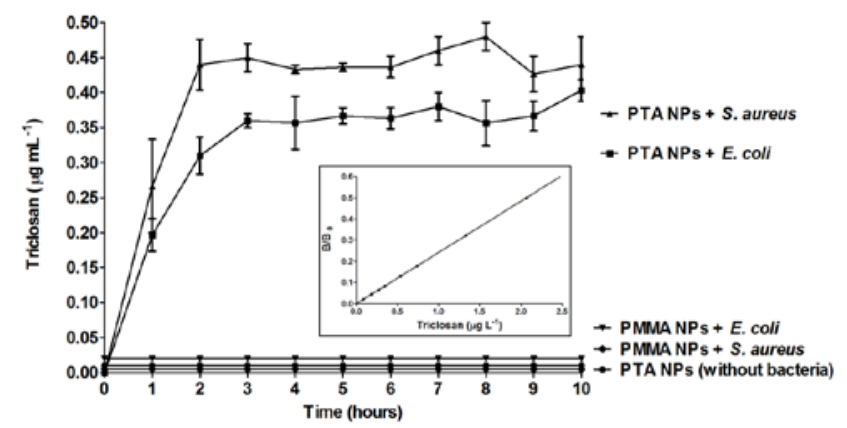

Figure 7: Direct NPs-cells interactions induced Triclosan release from PTA NPs. Monitoring of total triclosan released from PTA NPs $\left(50 \mu \mathrm{g} \mathrm{mL}^{-1}\right)$ incubated with $E$. coli and $S$. aureus. PTA incubated without bacteria served as control. Error bars represent the standard deviation of three independent experiments conducted in triplicate. The Inset represents a dose-response curve of absorbance vs. triclosan concentration, generated using results obtained from standard solutions. Triclosan concentration present in the main figure was determined directly from this curve.

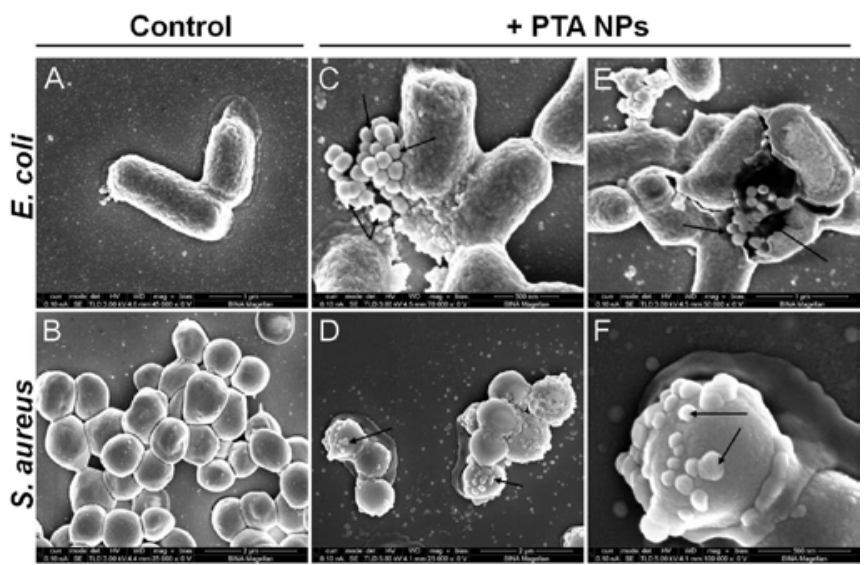

Figure 8: Scanning electron microscopy (SEM) of PTA NPs-treated and untreated cells. SEM micrographs of $E$. coli and $S$. aureus: untreated $E$. coli (A) and S. aureus (B); E. coli (C and E) and S. aureus (D and F) 3 and $2 \mathrm{~h}$ respectively, after exposure to PTA NPs $\left(50 \mu \mathrm{g} \mathrm{mL}^{-1}\right)$. Arrows indicate the presence of PTA NPS.

those concentrations were not found to be lethal when using free biocide (dashed lines in Figures 5A-B). On the other hand, when examining triclosan concentrations as measured after incubating PTA and control NPs without the presence of bacteria, it was reasonable to conclude that no triclosan was released. Taking together the data suggests that in order to activate the NPs and release triclosan, the direct presence of bacteria is obligatory. In other words, no harmful triclosan can leach out from the polymer on its own. This highlights the beneficial environmentally-friendly aspect of this system.

To further characterize the interaction of bacteria with these nanoparticles, we have taken SEM pictures of both E. coli and S. aureus (Figure 8) 3 and 2 hours after exposure respectively, where triclosan levels have reached plateau $\left(0.36 \mu \mathrm{g} \mathrm{ml}^{-1}\right.$ for E. coli and $0.44 \mu \mathrm{g} \mathrm{ml}^{-1}$ for S. aureus, according to Figure 7). Untreated bacteria (Figure $8 \mathrm{~A}$ and $8 \mathrm{~B}$ ) showed a normal size and typical morphologies for Gram positive and negative strains compared to treated cells. After a short treatment, PTA NPs were found aggregated on membranes and cell surfaces appeared to be altered with ruptured membranes and abnormal morphologies (Figure 8C-E).

\section{Conclusions}

We have designed, synthesized, and fully characterized a novel and environmentally friendly nanosized polyacrylate matrix that upon enzymatic degradation can release the FDA-approved antimicrobial agent, triclosan. The release of triclosan from these NPs is accomplished in a controlled and a quantifiable manner. Triclosan was covalently linked inside the polymeric NPs that are thus intrinsically designed to withhold the release of the biocide without any prior direct interaction with the pathogenic bacteria. Biochemical studies of these NPs established the required role of triclosan itself in the antimicrobial activity of these NPs. Furthermore, the quantification experiments showed that after NPs activation, i.e. an adhesion step to the pathogens, a steady concentration of triclosan was maintained for a long period of time, serving as a reservoir for prolonged and controlled triclosan release. It also supported the fact that a direct interaction was needed in order to activate the NPs. The combined set of results opens the path for future development of these polymeric nanomaterials for various biomedical and technological applications.

\section{Supporting Information}

Supporting Information is available online or from the author.

\section{References}

1. Legrand P, Barratt G, Mosqueira V, Fessi H, Devissaguet JP (1999) Polymeric nanocapsules as drug delivery systems: A review. STP Pharma Sciences 9 : 411-418.

2. Soppimath KS, Aminabhavi TM, Kulkarni AR, Rudzinski WE (2001) Biodegradable polymeric nanoparticles as drug delivery devices. J Control Release 70: 1-20.

3. Rollerova E, Scsukova S, Jurcovicova J, Mlynarcikova A, Szabova E, et al (2011) Polymeric nanoparticles - targeted drug delivery systems for treatment of CNS disorders and their possible endocrine disrupting activities. Endocr Regul 45: 49-60.

4. Chan JM, Valencia PM, Zhang L, Langer R, Farokhzad OC (2010) Polymeric nanoparticles for drug delivery. Cancer Nanotechnol 624: 163-175.

5. Kumari A, Yadav SK, Yadav SC (2010) Biodegradable polymeric nanoparticles based drug delivery systems. Colloids Surf B Biointerfaces 75: 1-18.

6. Fieber W, Herrmann A, Ouali L, Velazco MI, Kreutzer G, et al. (2007) Nmr diffusion and relaxation studies of the encapsulation of fragrances by amphiphilic multiarm star block copolymers. Macromolecules 40: 5372-5378.

7. Giri S, Trewyn BG, Lin VS (2007) Mesoporous silica nanomaterial-based biotechnological and biomedical delivery systems. Nanomedicine (Lond) 2: 99-111.

8. Hartmann M (2005) Ordered mesoporous materials for bioadsorption and biocatalysis. Chem Mater 17: 4577-4593.

9. Vallet-Regí M, Balas F, Arcos D (2007) Mesoporous materials for drug delivery Angew Chem Int Ed 46: 7548-7558.

10. Flesch C, Delaite C, Dumas P, Bourgeat-Lami E, Duguet E (2004) Grafting of poly(e-caprolactone) onto maghemite nanoparticles. J Polym Sci, Part A Polym Chem 42: 6011-6020.

11. Jones RD, Jampani HB, Newman JL, Lee AS (2000) Triclosan: A review of effectiveness and safety in health care settings. Am J Infect Control 28: 184196.

12. McMurry LM, Oethinger M, Levy SB (1998) Triclosan targets lipid synthesis Nature 394: 531-532.

13. Levy CW, Roujeinikova A, Sedelnikova S, Baker PJ, Stuitje AR, et al. (1999) Molecular basis of triclosan activity. Nature 398: 383-384. 
Citation: Igor M, Yonit B, Jonathan L, Ehud B, Jean-Paul L (2012) An Increased Efficiency of Triclosan Delivery by Novel Acrylate-Based Nanoparticles. J Nanomed Nanotechol S11:001. doi:10.4172/2157-7439.S11-001

14. Heath RJ, Rubin JR, Holland DR, Zhang E, Snow ME, et al. (1999) Mechanism of triclosan inhibition of bacterial fatty acid synthesis. J Biol Chem 274: 11110 11114

15. Baldock C, Rafferty JB, Stuitje AR, Slabas AR, Rice DW (1998) The X-ray structure of Escherichia coli enoyl reductase with bound NAD+ at $2.1 \mathrm{~A}$ resolution. J Mol Biol 284: 1529-1546.

16. Kalyon BD, Olgun U (2001) Antibacterial efficacy of triclosan-incorporated polymers. Am J Infect Control 29: 124-125.

17. Pei A, Shen Z, Yang G (2007) Preparation of $\mathrm{TiO}_{2}$ nanocapsules for loading and release of antimicrobial triclosan molecules. Mater Lett 61: 2757-2760.

18. Lu J, Hill MA, Hood M, Greeson Jr DF, Horton JR, et al. (2001) Formation of antibiotic, biodegradable polymers by processing with Irgasan DP300R (triclosan) and its inclusion compound with $\beta$-cyclodextrin. J Appl Polym Sci 82: 300-309.

19. Maestrelli F, Mura P, Alonso MJ (2004) Formulation and characterization of triclosan sub-micron emulsions and nanocapsules. J Microencapsul 21: 857 864

20. Iconomopoulou SM, Andreopoulou AK, Soto A, Kallitsis JK, Voyiatzis GA (2005) Incorporation of low molecular weight biocides into polystyrene-diviny benzene beads with controlled release characteristics. J Control Release 102: 223-233.

21. Kockisch S, Rees GD, Tsibouklis J, Smart JD (2005) Mucoadhesive, triclosanloaded polymer microspheres for application to the oral cavity: preparation and controlled release characteristics. Eur J Pharm Biopharm 59: 207-216.

22. Piñón-Segundo E, Ganem-Quintanar A, Alonso-Pérez V, Quintanar-Guerrero D (2005) Preparation and characterization of triclosan nanoparticles for periodontal treatment. Int J Pharm 294: 217-232.

23. Qian L, Guan Y, Xiao H (2008) Preparation and characterization of inclusion complexes of a cationic beta-cyclodextrin polymer with butylparaben or triclosan. Int J Pharm 357: 244-251.

24. Kim JC, Song ME, Lee EJ, Park SK, Rang MJ, et al. (2001) Preparation and characterization of triclosan-containing microcapsules by complex coacervation. J Dispers Sci Technol 22: 591-596.

25. Rule KL, Ebbett VR, Vikesland PJ (2005) Formation of chloroform and chlorinated organics by free-chlorine-mediated oxidation of triclosan. Environ Sci Technol 39: 3176-3185.

26. Tixier C, Singer HP, Canonica S, Muller SR (2002) Phototransfomation of ticlosan in surface waters: a relevant elimination process for this widely used biocide--laboratory studies, field measurements, and modeling. Environ Sci Technol 36: 3482-3489.
27. Dann AB, Hontela A (2011) Triclosan: environmental exposure, toxicity and mechanisms of action. J Appl Toxicol 31: 285-311.

28. Cho WJ, Ha CS, Oh ST (1995) Synthesis and biocidal activities of polymer ii. bactericidal activity of homopolymer of acdp and copolymer of AcDP with MMA. Journal of Macromolecular Science, Part A: Pure and Applied Chemistry 32: $479-495$

29. Amiri M, Shahrokhian S, Psillakis E, Marken F (2007) Electrostatic accumulation and determination of triclosan in ultrathin carbon nanoparticle composite film electrodes. Anal Chim Acta 593: 117-122.

30. Kugel AJ, Jarabek LE, Daniels JW, Vander Wal LJ, Ebert SM, et al. (2009) Combinatorial materials research applied to the development of new surface coatings XII: Novel, environmentally friendly antimicrobial coatings derived from biocide-functional acrylic polyols and isocyanates. J Coat Technol Res 6: 107-121.

31. Choi S, Jarabek L, Chisholm BJ, Boudjouk P (2007) The application of combinatorial/high-throughput methods to atom transfer radical polymerization of polymerizable triclosan derivatives. Polym Prepr (Am Chem Soc, Div Polym Chem) 48: 141-142.

32. Makarovsky I, Boguslavsky Y, Alesker M, Lellouche J, Banin E, et al. (2011) Novel Triclosan-Bound Hybrid-Silica Nanoparticles and their Enhanced Antimicrobial Properties. Adv Funct Mater 21: 4295-4304.

33. Heath RJ, Rock CO (2000) A triclosan-resistant bacterial enzyme. Nature 406 145-146.

34. Almog Y, Levy M (1981) Dispersion polymerization of styrene: Effect of surfactant. J Polym Sci: Polym Chem 19: 115-126.

35. Boguslavsky L, Baruch S, Margel S (2005) Synthesis and characterization of polyacrylonitrile nanoparticles by dispersion/emulsion polymerization process J Colloid Interface Sci 289: 71-85.

36. Heath RJ, Rock CO (1995) Enoyl-acyl carrier protein reductase (fabl) plays a determinant role in completing cycles of fatty acid elongation in Escherichia coli. J Biol Chem 270: 26538-26542.

37. Heath RJ, Rock CO (1996) Regulation of fatty acid elongation and initiation by acyl-acyl carrier protein in Escherichia coli. J Biol Chem 271: 1833-1836.

38. Marrakchi H, Dewolf WE Jr, Quinn C, West J, Polizzi BJ, et al. (2003) Characterization of Streptococcus pneumoniae enoyl-(acyl-carrier protein) reductase (FabK). Biochem J 370: 1055-1062.

39. Su W, Wang S, Wang X, Fu X, Weng J (2010) Plasma pre-treatment and TiO coating of PMMA for the improvement of antibacterial properties. Surf Coat Technol 205: 465-469. 